\title{
The value of 3D visualization operative planning system in ultrasound-guided percutaneous microwave ablation for large hepatic hemangiomas: a clinical comparative study
}

\author{
Xin Li ${ }^{\dagger}$, Chao An ${ }^{\dagger}$, Fangyi Liu, Zhigang Cheng, Zhiyu Han, Xiaoling Yu, Linan Dong, Jie Yu and Ping Liang*
}

\begin{abstract}
Background: To evaluate the value of a three dimension (3D)visualization operative planning system in ultrasoundguided percutaneous microwave ablation (US-PMWA) for large hepatic hemangiomas (LHHs).

Methods: Fifty-eight patients with LHHs were divided into 3D and 2D groups. The therapeutic efficacy was assessed by contrast-enhanced imaging during follow-up. Hepatic and renal function were examined. The complete ablation, tumor volume shrinkage, and complication rates were analyzed.

Results: The ablation time and energy of the 3D group were lower than those of the $2 \mathrm{D}$ group $(1152.0 \pm 403.9 \mathrm{~s}$ vs. $1379.7 \pm 375.8 \mathrm{~s}$ and $87,407.2 .9 \pm 50,387.0 \mathrm{~J}$ vs. $117,775.8 \pm 46,245.6 \mathrm{~J}, P=0.031$ and 0.021 , respectively). The $3 \mathrm{D}$ group had a higher complete ablation rate than the $2 \mathrm{D}$ group $(97.7 \pm 2.4 \%$ vs. $94.5 \pm 3.7 \%, P<0.001)$. The incidence of hemoglobinuria after ablation in the $3 \mathrm{D}$ group was lower than that in the $2 \mathrm{D}$ group $(32.0 \% \mathrm{vs} .57 .6 \%, P=0.047)$. The levels of alanine aminotransferase (ALT), aspartate aminotransferase (AST), alkaline phosphatase (ALP), and creatinine (Cre) after ablation in the 3D group were lower than those in the $2 \mathrm{D}$ group $(126.7 \pm 56.4 \mathrm{U} / \mathrm{L} \mathrm{vs} .210 .9 \pm 96.2 \mathrm{U} / \mathrm{L}$, $P<0.001 ; 141.0 \pm 60.8 \mathrm{U} / \mathrm{L}$ vs. $211.4 \pm 90.0 \mathrm{U} / \mathrm{L}, P=0.001 ; 57.3 \pm 17.6 \mathrm{U} / \mathrm{L}$ vs. $80.8 \pm 41.9 \mathrm{U} / \mathrm{L}, P=0.010 ;$ and $66.6 \pm 16.6 \mathrm{mmol} / \mathrm{L}$ vs. $84.5 \pm 39.6 \mathrm{mmol} / \mathrm{L}, P=0.037$, respectively). There were no significant differences in antenna insertion and the volume reduction rate between the groups. One patient developed acute kidney injury shortly after ablation in the $2 \mathrm{D}$ group and recovered after hemodialysis. No other severe complications occurred during the follow-up period.

Conclusions: The 3D visualization operative planning system has a relatively high clinical application value in providing scientific, reasonable, quantifiable, and individualized therapy for LHHs by US-PMWA.
\end{abstract}

Keywords: 3D visualization operative planning system, Microwave ablation, Large hepatic hemangiomas

\section{Background}

Hepatic hemangioma is the most frequently encountered solid benign liver neoplasm, with an incidence of 0.4 to $20 \%$ in the general population and accounting for $73 \%$ of all benign liver lesions [1-3]. There is no controversy concerning the management of incidentally identified and asymptomatic hepatic hemangiomas, which require

\footnotetext{
*Correspondence: liangping301@hotmail.com

${ }^{\dagger}$ Xin Li and Chao An contributed equally to this work.

Department of Interventional Ultrasound, Chinese PLA General Hospital, 28 Fuxing Road, Beijing 100853, China
}

no intervention or further observation if there are no adverse complications or effects on adjacent organs. Only large hepatic hemangiomas (LHHs) that lead to symptoms such as abdominal pain or distension, anemia, portal hypertension, obstructive jaundice, spontaneous or traumatic rupture, coagulopathy or serious psychological effects may require intervention [4-9]. However, the definition of LHHs varies in the literature. Some authors report hemangioma $>4 \mathrm{~cm}$ as large $[7,10,11]$, while a very small number of authors define those $>10 \mathrm{~cm}$ as LHH [12-14]. However, in most reports in the literature, 
LHHs are defined as being $\geq 5 \mathrm{~cm}$ and warranting therapy when they lead to clinical symptoms or the risk of life-threatening spontaneous rupture and hemorrhage $[5,7,15]$. In this study, $\mathrm{LHH}$ was defined as a hemangioma with a maximum diameter $\geq 5 \mathrm{~cm}$.

Surgical resection and surgical enucleation are the traditional modalities for the treatment of LHHs [9, 13, 16-18]. However, other therapies, including liver transplantation, transcatheter arterial embolization [19-22], radiation therapy [23, 24], thermal ablation (radiofrequency and microwave ablation) [3, 8, 11, 25-27], and medications (bevacizumab, sorafenib, cisplatin and bleomycin) [28, 29], have also been reported in the management of LHHs. In some cases, operative treatment of LHHs remains a challenge for surgeons because of massive intraoperative blood loss and difficulty in controlling bleeding [30, 31]. Compared with other ablation technique, the benefits of microwave ablation, which has a higher thermal efficiency, include fewer limitations due to the heat-sink effect and tissue charring and the achievement of a larger ablation volume in a shorter time, with better clinical effects [11, 32-34]. Therefore, microwave ablation is a better choice for the treatment of symptomatic LHHs.

Importantly, LHHs often compress surrounding vital structures, such as the gastric outlet, hepatic vein, portal vein, hepatic artery, bile duct, or inferior vena cava, which could increase the difficulty and risk of treatment [35-37]. Methods to protect surrounding organs and simultaneously achieve complete ablation are important. Moreover, hemoglobinuria and acute renal failure occurring after ablation have been reported in the literature, including cases requiring hemodialysis [10, 38]. Therefore, how to achieve scientific, objective, quantifiable, and individualized operative planning is a key issue concerning ablation. Operative planning is typically performed based on the spatial awareness and experience of operators' "human brain" using two-dimensional (2D) imaging data, which are highly subjective and abstract. The operators' evaluation is inconsistent with the actual situation in some cases and may lead to incomplete ablation or major complications [39]. A three dimensional (3D) visualization operation planning system not only displays the location and spatial relationship of the tumor with the surrounding structures, quantifies the tumor size and volume, predicates the time-temperature profile, and improves the safety and effectiveness of ablation but also enables planning of the implantation route and accurate positioning of the ablation antenna [40-42]. The purpose of this study was to explore the clinical value of a 3D visualization operative planning system in ultrasoundguided percutaneous microwave ablation (US-PMWA) for large hepatic hemangiomas compared to the $2 \mathrm{D}$ operative planning system.

\section{Methods}

\section{Patients and study design}

This single-center, retrospective study protocol was approved by the Ethics Committee of the Chinese PLA General Hospital (Beijing, China) and was conducted in accordance with the principles of the Declaration of Helsinki. From January 2011 to August 2018, 58 patients (43 females, 15 males; mean age $43.5 \pm 8.2$ years) with $58 \mathrm{LHHs}$ (mean maximum diameter $7.4 \pm 1.5 \mathrm{~cm}$, range $5-12.6 \mathrm{~cm}$ ) were divided into two groups. The 3D group included 25 patients who underwent US-PMWA with the aid of the self-developed 3D visualization operative planning system. The 2D group included 33 patients who underwent US-PMWA using the conventional 2D image operative planning methods.

The inclusion criteria for US-PMWA were as follows: (1) definite diagnosis of $\mathrm{LHH} \geq 5 \mathrm{~cm}$ based on the typical enhancement pattern on contrast-enhanced computed tomography (CT), magnetic resonance imaging (MRI), or contrast-enhanced ultrasound (CEUS); (2) clinical symptoms typically caused by LHHs present for at least 1 year, including abdominal pain, nausea, vomiting, abdominal fullness, and serious mental burden [10, 11]; (3) diagnoses of LHH pathologically proven by ultrasound (US)-guided core needle biopsy before ablation; and (4) prothrombin time $<25 \mathrm{~s}$; prothrombin activity $>40 \%$; and platelet count $>60$ cells $\times 10^{9} / \mathrm{L}$. The exclusion criteria were: (1) severe cardiopulmonary disease; (2) serious renal failure (creatinine above the normal level); (3) severe hepatic failure (aminotransferase and bilirubin greater than the twice the normal level). Written informed consent was obtained from all participating patients.

\section{D visualization operative planning system, US-PMWA, and auxiliary techniques \\ $3 D$ visualization operative planning system}

All patients with LHH underwent conventional ultrasound, CEUS, and/or CT/MRI to delineate the target tumor within 7 days before ablation. A desktop computer (Lenovo) with an Intel Core i5 processor for an empirical study in our department was used to perform $3 \mathrm{D}$ visualization preoperative planning. A series of CT or MRI data $(0.625 \mathrm{~mm}$ - or $2.5 \mathrm{~mm}$-thick slices) of the LHHs before MWA were converted to DICOM format and then imported into the 3D visualization treatment platform (Hokai Company, Zhuhai, China). Our group originally developed the $3 \mathrm{D}$ visualization platform software that has novel functions as follows: 1) rapid segmentation in the target (within $2 \mathrm{~min}$ ); 2) volume calculation in the target; 3 ) simulation of the thermal field; 4) interactive pre-ablative planned strategy by manual operation; and 5) assessment of ablative effect by tumor mapping. The graphical user interface displayed the real-time simulation $2 \mathrm{D}$ ultrasound guided planning and 
the $3 \mathrm{D}$ visualization planning, as well as the planning path from the transverse, coronal, and sagittal planes. The application of 3D visualization technology enables a radiologist to perform various operations on the 3D image, such as free movement, rotation, and scaling, to develop a puncture plan by seeing more intuitively. The liver mass with a 5-mm tumor-free margin, vessels, and surrounding vital structures was segmented and reconstructed, which can be demonstrated via stereo display in the $3 \mathrm{D}$ visualization.

The 3D operation planning system of US-PMWA should abide by the following principles: (1) conformational ablation was applied while covering the entire tumor only; (2) avoid ablation of vital structures, particularly the secondary biliary duct, arteries and veins, or intestinal tract; and (3) minimize the distance of electrode insertion trajectories while avoiding puncture pathways via critical structures. The planning system was designed to iterate these goals until a reasonable and feasible plan was achieved [39].

\section{Us-PMWA}

The ablations were performed in our institution, and all patients were hospitalized. The microwave system (KY-2000, Kangyou Medical, Nanjing, China) comprised a MW generator, flexible coaxial cable, and cooled-shaft antenna. A $2450 \mathrm{MHz}$ or $915 \mathrm{MHz} \mathrm{MW}$ system was used. The $2450 \mathrm{MHz}$ MW system consisted of three independent MW generators, three flexible coaxial cables, and three water-pumping machines that can simultaneously drive three 15 -gauge cooled-shaft antennae $(1.1 \mathrm{~cm}$ antenna tip). The $915 \mathrm{MHz}$ MW system consisted of two independent MW generators, two flexible coaxial cables, and two water-pumping machines that can simultaneously drive two 15-gauge cooled-shaft antennae $(2.2 \mathrm{~cm}$ antenna tip). The MW system generators were capable of producing 1-100 W of power output. The 15-G cooled-shaft antenna was coated with Teflon to prevent adhesion with dual channels inside the antenna shaft, through which distilled water continuously circulated via a peristaltic pump that could cool the shaft to prevent overheating.

The patient was unconscious, under intravenous anesthesia (propofol, $6-12 \mathrm{mg} / \mathrm{kg} / \mathrm{h}$; ketamine, $1-2 \mathrm{mg} / \mathrm{kg}$ ), during ablation in the operating room. All treatments were carried out by two operators with more than 5 years of ablation experience according to the operative plan. If the tumors and tumor-feeding arteries were not well visualized with conventional US, CEUS-guided ablation with SonoVue (Bracco, Milan, Italy) was performed. US-guided biopsy was performed using an 18-G cutting needle (C. R. Bard, Japan) before ablation. First, the tumor-feeding artery of the hemangioma was ablated with higher power $(60-80 \mathrm{~W})$ until no blood flow or hyperenhancement was visible on color Doppler flow imaging (CDFI) and CEUS. An 18-G percutaneous transhepatic cholangiography (PTC) needle (Hakko, Japan) was inserted into the hemangioma to simultaneously aspirate the blood from the blood sinus of the hemangioma. Two antennae were subsequently implanted in the proper location of the $\mathrm{LHH}$ according to the 3D visualization operative planning system. The hyperechoic area of ablation was monitored by greyscale ultrasound, and the endpoint of ablation was determined. The antennae tracks were routinely cauterized to avoid bleeding during withdrawal.

\section{Auxiliary techniques}

According to the preoperative contrast-enhanced CT or MRI imaging or 3D visualization operative planning system evaluation, hydrodissection and thermal monitoring techniques were applied for LHHs abutting vital structures to avoid thermal injury. After application of a local anesthetic (1\% lidocaine), a 16-G intravenous catheter (BD Angiocath; Sandy, UT, USA) was inserted into the peritoneal cavity between the edge of the liver and the abutting gastrointestinal tract using US guidance. A sufficient amount of chilled normal saline was delivered until a separation of greater than $0.5 \mathrm{~cm}$ was achieved and maintained during the procedure. Then, 21-G thermocouple needles were equipped on the MWA system, which are easily visualized by US during ablation, for LHHs abutting vital structures. Based on our experimental evidence, the temperature cut-off of ablation was set at $60^{\circ} \mathrm{C}$. If the measured temperature reached $60^{\circ} \mathrm{C}$, ablation was immediately terminated and activated again after the temperature decreased to $50^{\circ} \mathrm{C}[10,11]$.

\section{Therapeutic effect evaluation and follow-up}

The therapeutic effect was assessed by ultrasound at 1 , 3 , 6, and 12 months for 1 year and then at 6-month intervals after ablation during the follow-up period. If a recurrence tumor was detected by more than $40-50 \%$ of the ablation zone, contrast-enhanced imaging was performed. Technical effectiveness was defined as $90-100 \%$ of the hemangiomas ablated on contrast enhanced imaging within 3 days after ablation. The complete ablation was evaluated via an enhancement on contrast-enhanced imaging and calculated by the post 3D planning system (Fig. 1a-l). The complete ablation rate and tumor volume shrinkage rate were analyzed. Complications were classified according to the Society of Interventional Radiology Classification system for Complications by Outcome [43]. The hepatic and renal function and routine urine test results were examined before and 1 day after ablation. Once abnormal results were detected, medical treatment was provided until resolution occurred. The number of antenna insertions, tumor volume, ablation time, ablation energy, and aspiration blood volume were recorded and analyzed. 

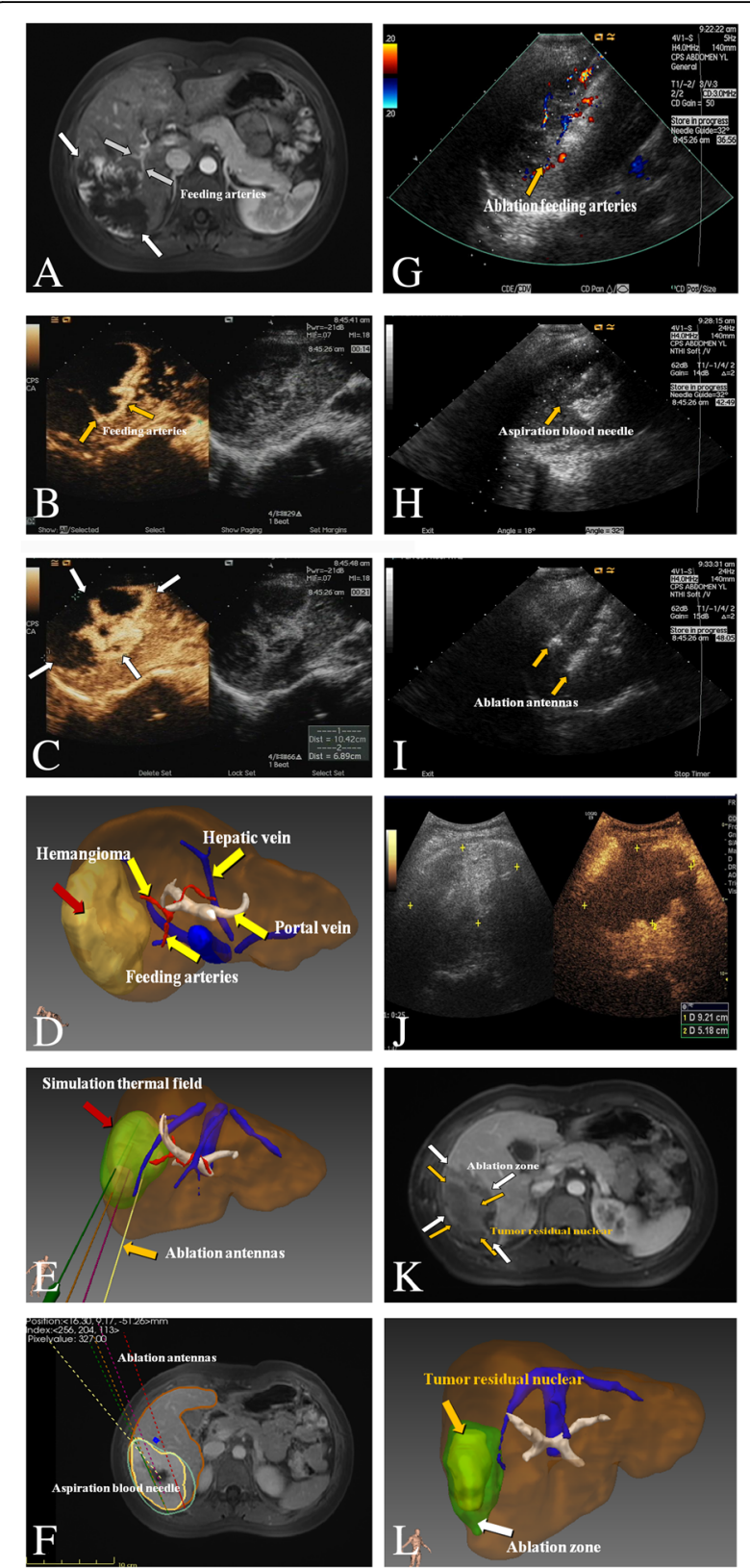

Fig. 1 Images of a 28-year-old woman who underwent US-PMWA for larger hepatic cavernous hemangioma (LHH) $(10.4 \mathrm{~cm} \times 6.9$ $\mathrm{cm} \times 8.4 \mathrm{~cm}$ ) assisted by a 3D visualization operative planning system. a Preoperative contrast-enhanced MRI showed the LHH with peripheral nodular hyperenhancement in the artery phase in the right lobe accompanied by two feeding arteries (white arrows). b-c Preoperative contrast-enhanced ultrasound imaging also showed the LHH with peripheral nodular hyperenhancement in the artery phase in the right lobe (white arrow) companying with two feeding arteries (yellow arrow). $\mathbf{d}$-f $3 D$ visualization operative planning system showed the location and relationship with the tumor and the surrounding organs and the feed arteries stereoscopically (yellow arrow), quantized the volume of the liver and LHH (liver: $1396.94 \mathrm{ml}$; LHH:197 ml), projected the number and the pathway of the ablation antenna implantation, the ablation time and energy, simulated the thermal field, and provided the location of the aspiration blood needle, which is at the center of the LHH. $\mathbf{g}$-i The ablation procedure was performed according to the panning. First, the arteries were ablated by higher power $(\mathbf{g})$ and blood was aspirated from the sinus (h). Two antennas were subsequently implanted in the LHH according to planning with two insertion and eight ablation points (i) (yellow arrow). $\mathbf{j}-\mathbf{I}$ After ablation, the CEUS image immediately after ablation showed no enhancement in the ablation zone with a shrunk size $(\mathbf{j})$. In the MRI image 3 days after ablation, the tumor residual nuclear and ablation zones were clearly demonstrated, and the residual nuclear zone had largely shrunk $(\mathbf{k})$. The post-operative 3D visualization system safely showed the tumor residual nuclear and ablation zones and the surrounding organs; the volumes of the tumor residual nuclear and ablation zones and the reduction rate of the volume were also calculated $(58.6 \mathrm{ml}, 131.0 \mathrm{ml}$ and $70.3 \%)$ (I) (yellow and white arrows)

\section{Statistical analysis}

Data were analyzed using SPSS 21.0 for Windows (SPSS Inc., Chicago, IL, USA). Continuous data are expressed as the mean \pm standard deviation (SD). The paired $t$-test or $x^{2}$ test was used to compare values between two groups. The comparison of continuous variables between two groups was performed via Student's t-test or the Mann-Whitney U-test. Changes in the hepatic and renal function before and after ablation were compared using paired t-tests. Pearson chi-squared analysis or Fisher exact tests were performed to compare the categorical variables. $P$ values $<0.05$ were considered statistically significant.

\section{Results}

Basic characteristics of patients, tumors, and ablations

Table 1 reports all patient, LHH, and ablation data. Among 58 LHHs, 11 lesions were located in the left lobe compressing the gastric outlet; 47 lesions were located in the right lobe, with 10 lesions abutting the intestinal tract. Hydrodissection and thermal monitoring techniques were applied for 21 patients with a $100 \%$ onetime success rate. All patients successfully underwent a single ablation according to $2 \mathrm{D}$ or $3 \mathrm{D}$ pre-operative planning. The aspiration blood volume was $108.5 \pm 79.2 \mathrm{ml}$ (14-359 $\mathrm{ml})$, the ablation energy was $104,685.9 \pm 49,997.8 \mathrm{~J}$ $(3000-226,400 \mathrm{~J})$, the ablation time was $1281.6 \pm 401.2 \mathrm{~s}$ 
Table 1 The characteristics of patients, tumors and ablations of LHHs patients

\begin{tabular}{ll}
\hline Parameters & Date \\
\hline Patients (No.) & 58 \\
Male/Female (No.) & $15 / 43$ \\
Age (years) & $43.5 \pm 8.2(28-60)$ \\
Tumors (No.) & 58 \\
Mean max diameter (cm) & $7.4 \pm 1.5(5-12.6)$ \\
Volume of tumor (ml) & $136.9 \pm 79.4(26.8-375.9)$ \\
Location (right/left) & $47 / 11$ \\
Hydrodissection (ml) & 21 \\
Thermal monitoring & 21 \\
Aspiration blood volume (ml) & $108.5 \pm 79.2(14-359)$ \\
Ablation energy ( $)$ & $104685.9 \pm 49997.8(3000-226400)$ \\
Ablation time (s) & $1281.6 \pm 401.2(480-2230)$ \\
Antenna insertion (No.) & $4.4 \pm 1.6(2-9)$ \\
Complete ablation rate (\%) & $95.9 \pm 3.5(90-100)$ \\
Reduction rate of volume (\%) & $52.1 \pm 8.4(35.2-76.7)$ \\
Rate of hemoglobinuria (\%) & $46.5(27 / 58)$ \\
\hline
\end{tabular}

(480-2230 s), the antenna insertion was $4.4 \pm 1.6$ (2-9), the complete ablation rate was $95.9 \pm 3.5 \%$ (90$100 \%)$, and the reduction rate of the tumor volume was $52.1 \pm 8.4 \%$ (35.2-76.7\%).

\section{Changes in hepatic and renal function before and after ablation}

The preoperative characteristics and postoperative findings are reported in Table 2 . The values of alanine aminotransferase (ALT), aspartate aminotransferase (AST), total bilirubin (TB), direct bilirubin (DBIL), and creatinine (Cre) after ablation were higher than the values before ablation, with significant differences $((22.8 \pm 16.9 \mathrm{U} / \mathrm{L}(6.8-84.1)$ vs. $174.6 \pm 91.1 \mathrm{U} / \mathrm{L} \quad(37-543.9), \quad P<0.001 ; \quad 19.0 \pm 7.0 \mathrm{U} / \mathrm{L}$

Table 2 The changes of liver and renal function before and after ablation in LHHs patients

\begin{tabular}{llll}
\hline Parameters & Pre-operative & Post-operative & $P$ value \\
\hline ALT(U/L) & $22.8 \pm 16.9(6.8-84.1)$ & $174.6 \pm 91.1(37-543.9)$ & $<0.001^{*}$ \\
AST(U/L) & $19.0 \pm 7.0(10.6-40.0)$ & $181.0 \pm 85.7(32.0-479.9)$ & $<0.001^{*}$ \\
ALP $(\mathrm{U} / \mathrm{L})$ & $64.3 \pm 16.5(39.4-98.8)$ & $70.7 \pm 35.4(19.4-178.9)$ & 0.179 \\
GGT (U/L) & $24.2 \pm 13.6(6.7-80.2)$ & $33.0 \pm 19.2(1.9-92.8)$ & 0.150 \\
Cre (umol/L) & $59.6 \pm 13.0(34.5-92.9)$ & $76.1 \pm 32.7(38.2-204.0)$ & $0.010^{*}$ \\
BUN (mmol/L) & $4.5 \pm 1.2(2.6-7.9)$ & $5.6 \pm 4.5(1.3-26.4)$ & 0.146 \\
STB (U/L) & $12.3 \pm 4.6(5.4-26.6)$ & $30.5 \pm 14.3(3.8-74.1)$ & $<0.001^{*}$ \\
DBIL (U/L) & $4.9 \pm 1.4(2.3-7.8)$ & $9.6 \pm 8.1(1.2-59.2)$ & $<0.001^{*}$
\end{tabular}

$A L T$ alanine aminotransferase, AST aspartate aminotransferase, $A L P$ alkaline phosphatase, GGT gamma-glutamyl transpeptidase, Cre creatinine, BUN blood urea nitrogen, STB total bilirubin, DBIL direct bilirubin; *-pre: index of preablation; *-post: index of postablation
(10.6-40.0) vs. $181.0 \pm 85.7 \mathrm{U} / \mathrm{L} \quad(32.0-479.9), \quad P<0.001$; $12.3 \pm 4.6 \mathrm{U} / \mathrm{L}(5.4-26.6)$ vs. $30.5 \pm 14.3 \mathrm{U} / \mathrm{L}(3.8-74.1)$, $P<0.001 ; 4.9 \pm 1.4 \mathrm{U} / \mathrm{L} \quad(2.3-7.8)$ vs. $9.6 \pm 8.1 \mathrm{U} / \mathrm{L} \quad(1.2-$ 59.2), $P<0.001$; and $59.6 \pm 13.0 \mathrm{mmol} / \mathrm{L}(34.5-92.9)$ vs. $76.1 \pm 32.7 \mathrm{mmol} / \mathrm{L}$ (38.2-204.0), $P=0.010$, respectively). Although the indexes of alkaline phosphatase (ALP), gamma-glutamyl transpeptidase (GGT), and blood urea nitrogen (BUN) after ablation were higher than the values before ablation, no significant differences were identified $(64.3 \pm 16.5 \mathrm{U} / \mathrm{L}(39.4-98.8)$ vs. $70.7 \pm 35.4 \mathrm{U} / \mathrm{L}$ (19.4-178.9), $\quad P=0.179 ; \quad 24.2 \pm 13.6 \mathrm{U} / \mathrm{L}(6.7-80.2) \quad$ vs. $33.0 \pm 19.2 \mathrm{U} / \mathrm{L}(1.9-92.8), P=0.150$; and $4.5 \pm 1.2 \mu \mathrm{mol} / \mathrm{L}$ $(2.6-7.9)$ vs. $5.6 \pm 4.5 \mu \mathrm{mol} / \mathrm{L} \quad(1.3-26.4), \quad P=0.146$, respectively). All data suggested that the effects of US-PMWA for LHH on hepatic and renal functions were transient and resolved rapidly with medical treatment. While the incidence rate of hemoglobinuria was $46.5 \%$ (27/58), only 1 patient developed acute renal failure; this patient recovered after hemodialysis. No other severe complications occurred during the perioperative and follow-up periods.

\section{Comparison of clinical characteristics between the 3D planning group and 2D planning group}

The characteristics of the $3 \mathrm{D}$ and $2 \mathrm{D}$ groups before ablation are shown in Table 3. There were no significant statistical differences between the groups in terms of age, mean maximal tumor diameter, tumor volume, and aspiration blood volume $(43.8 \pm 8.8$ years $(28-57)$ vs. $43.2 \pm 7.9$ years $(31-60) ; 7.5 \pm 1.7 \mathrm{~cm} \mathrm{(5-12.5)} \mathrm{vs.} 7.2 \pm 1.3$ $\mathrm{cm}(5.1-10.8) ; 148.2 \pm 89.1 \mathrm{ml}(26.8-301.1)$ vs. $128.4 \pm$ $71.4 \mathrm{ml}(39.8-375.8)$; and $108.4 \pm 84.9 \mathrm{ml} \mathrm{(14-284)}$ vs.

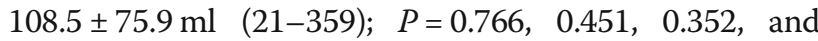
0.996 , respectively). No significant differences were identified in hepatic and renal function as measured by ALT, AST, ALP, GGT, Cre, BUN, STB, and DBIL before ablation $(20.3 \pm 15.2 \mathrm{U} / \mathrm{L}(6.9-84.0)$ vs. $24.7 \pm 18.0 \mathrm{U} / \mathrm{L}(9.0-$ $107.5) ; 19.2 \pm 6.5 \mathrm{U} / \mathrm{L}(11.8-38.6)$ vs. $18.9 \pm 7.4 \mathrm{U} / \mathrm{L}(10.8-$ $34.6) ; 63.0 \pm 18.1 \mathrm{U} / \mathrm{L}(40.4-98.8)$ vs. $65.2 \pm 15.4 \mathrm{U} / \mathrm{L}$ (39.894.3); $23.5 \pm 16.6 \mathrm{mmol} / \mathrm{L} \quad(8.6-38.1) \quad$ vs. $24.8 \pm 11.0$ $\mathrm{mmol} / \mathrm{L}(6.7-48.2) ; 63.0 \pm 8.9 \mu \mathrm{mol} / \mathrm{L}(49.9-78.7)$ vs. $57.2 \pm$ $15.1 \mu \mathrm{mol} / \mathrm{L}(37.6-85.9) ; 4.7 \pm 1.2 \mathrm{mmol} / \mathrm{L}(2.8-7.8)$ vs. $4.2 \pm$ $1.0 \mathrm{mmol} / \mathrm{L} \quad(2.6-6.4) ; \quad 12.3 \pm 3.6 \mathrm{U} / \mathrm{L} \quad(6.4-20.1) \quad$ vs. $12.4 \pm 5.3 \mathrm{U} / \mathrm{L}(5.4-26.3) ;$ and $4.5 \pm 1.3 \mathrm{U} / \mathrm{L}(2.3-7.5)$ vs. $5.2 \pm 1.5 \mathrm{U} / \mathrm{L}(2.9-7.9) ; P=0.330,0.872,0.618,0.709$, $0.092,0.055,0.923$, and 0.070 , respectively). Thus, the baseline data of the two groups showed no differences, and the outcomes were comparable.

Table 3 reports the results after ablation in the 3D and $2 \mathrm{D}$ groups. The ablation time and energy of the 3D group were lower than those of the 2D group (1152.0 \pm $403.9 \mathrm{~s}(600-1890)$ vs. $1379.7 \pm 375.8 \mathrm{~s}(810-2230)$ and $87,407.2 .9 \pm 50,387.0 \mathrm{~J}(3000-226,400)$ vs. $117,775.8 \pm$ 46,245.6 J (6000-200,800); $P=0.031$ and 0.021 , 
Table 3 The comparison of clinical parameters between 3D planning group and 2D planning group group patients in LHHs patients

\begin{tabular}{|c|c|c|c|}
\hline Parameters & 3D planning group & 2D planning group & $P$ value \\
\hline Age (years) & $43.8 \pm 8.8(28-57)$ & $43.2 \pm 7.9(31-60)$ & 0.766 \\
\hline Mean max diameter (cm) & $7.5 \pm 1.7(5-12.5)$ & $7.2 \pm 1.3(5.1-10.8)$ & 0.451 \\
\hline Volume of tumor (ml) & $148.2 \pm 89.1(26.8-301.1)$ & $128.4 \pm 71.4(39.8-375.8)$ & 0.352 \\
\hline Aspiration blood volume (ml) & $108.4 \pm 84.9(14-284)$ & $108.5 \pm 75.9(21-359)$ & 0.996 \\
\hline Ablation power $(J)$ & 87407.2.9 $\pm 50387.0(3000-226400)$ & $117775.8 \pm 46245.6(6000-200800)$ & $0.021^{*}$ \\
\hline Ablation time (s) & $1152.0 \pm 403.9(600-1890)$ & $1379.7 \pm 375.8(810-2230)$ & $0.031^{*}$ \\
\hline Antenna insertion & $4.8 \pm 1.9(2-9)$ & $4.1 \pm 1.2(2-6)$ & 0.068 \\
\hline Complete ablation rate (\%) & $97.7 \pm 2.4(93-100)$ & $94.5 \pm 3.7(90-100)$ & $0.0004^{*}$ \\
\hline Reduction rate of volume (\%) & $53.4 \pm 7.5(43.5-76.0)$ & $51.1 \pm 9.0(35.2-76.7)$ & 0.299 \\
\hline Case of hemoglobinuria (No.) & $8 / 17$ & $19 / 14$ & $0.047^{*}$ \\
\hline ALT-pre(U/L) & $20.3 \pm 15.2(6.9-84.0)$ & $24.7 \pm 18.0(9.0-107.5)$ & 0.330 \\
\hline AST-pre(U/L) & $19.2 \pm 6.5(11.8-38.6)$ & $18.9 \pm 7.4(10.8-34.6)$ & 0.872 \\
\hline ALP-pre(U/L) & $63.0 \pm 18.1(40.4-98.8)$ & $65.2 \pm 15.4(39.8-94.3)$ & 0.618 \\
\hline GGT-pre(U/L) & $23.5 \pm 16.6(8.6-38.1)$ & $24.8 \pm 11.0(6.7-48.2)$ & 0.709 \\
\hline Cre-pre(umol/L) & $63.0 \pm 8.9(49.9-78.7)$ & $57.2 \pm 15.1(37.6-85.9)$ & 0.092 \\
\hline BUN-pre(mmol/L) & $4.7 \pm 1.2(2.8-7.8)$ & $4.2 \pm 1.0(2.6-6.4)$ & 0.055 \\
\hline STB-pre (U/L) & $12.3 \pm 3.6(6.4-20.1)$ & $12.4 \pm 5.3(5.4-26.3)$ & 0.923 \\
\hline DBIL-pre (U/L) & $4.5 \pm 1.3(2.3-7.5)$ & $5.2 \pm 1.5(2.9-7.9)$ & 0.070 \\
\hline ALT-post (U/L) & $126.7 \pm 56.4(37.0-224.1)$ & $210.9 \pm 96.2(94.8-345.0)$ & $0.0002^{*}$ \\
\hline AST-post (U/L) & $141.0 \pm 60.8(40.2-237.0)$ & $211.4 \pm 90.0(32-294.5)$ & $0.001^{*}$ \\
\hline ALP-post(U/L) & $57.3 \pm 17.6(34.6-79.4)$ & $80.8 \pm 41.9(36.4-178.0)$ & $0.010^{*}$ \\
\hline GGT-post(U/L) & $26.5 \pm 17.6(9.4-64.2)$ & $37.8 \pm 19.1(8.8-92.8)$ & 0.060 \\
\hline Cre-post(umol/L) & $66.6 \pm 16.6(51.3-117.0)$ & $84.5 \pm 39.6(40.8-204.0)$ & $0.037^{*}$ \\
\hline BUN-post(mmol/L) & $4.4 \pm 2.6(1.3-13.8)$ & $6.6 \pm 5.3(2.4-18.1)$ & 0.061 \\
\hline STB-post (U/L) & $28.0 \pm 14.4(8.7-70.7)$ & $32.4 \pm 14.2(3.8-74.1)$ & 0.252 \\
\hline DBIL-post (U/L) & $8.4 \pm 4.6(1.2-17.7)$ & $10.6 \pm 10.0(3.4-49.4)$ & 0.428 \\
\hline
\end{tabular}

$A L T$ alanine aminotransferase, $A S T$ aspartate aminotransferase, $A L P$ alkaline phosphatase, GGT gamma-glutamyl transpeptidase, Cre creatinine, $B U N$ blood urea nitrogen, STB total bilirubin, DBIL direct bilirubin; *-pre: index of preablation; *-post: index of postablation

respectively). The 3D group had a higher complete ablation rate than that of the 2D group $(97.7 \pm 2.4 \%$ (93-100) vs. $94.5 \pm 3.7 \%(90-100), \quad P<0.001)$. The incidence of hemoglobinuria after ablation in the $3 \mathrm{D}$ group was lower than that of the 2D group $(32.0 \%$ vs. $57.6 \%, P=0.047)$. The hepatic function indices of ALT, AST, and ALP and the renal function index of Cre in the $3 \mathrm{D}$ group after ablation were lower than those of the $2 \mathrm{D}$ group $(126.7 \pm 56.4 \mathrm{U} / \mathrm{L}(37.0-224.1)$ vs. $210.9 \pm 96.2 \mathrm{U} / \mathrm{L}$ (94.8-345.0), $P<0.001 ; 141.0 \pm 60.8 \mathrm{U} / \mathrm{L}(40.2-237.0)$ vs. $211.4 \pm 90.0 \mathrm{U} / \mathrm{L} \quad(32-294.5), \quad P=0.001 ; \quad 57.3 \pm 17.6 \mathrm{U} / \mathrm{L}$ (34.6-79.4) vs. $80.8 \pm 41.9 \mathrm{U} / \mathrm{L}$ (36.4-178.0), $P=0.010$; and $66.6 \pm 16.6 \mu \mathrm{mol} / \mathrm{L} \quad(51.3-117.0) \quad$ vs. $84.5 \pm 39.6 \mu \mathrm{mol} / \mathrm{L}$ (40.8-204.0), $P=0.037$, respectively). There were trends towards differences in the antenna insertion and tumor volume reduction rate between the groups, without significant differences $(4.8 \pm 1.9$ (2-9) vs. $4.1 \pm 1.2$ (2-6); $53.4 \pm 7.5 \% \quad(43.5-76.0) \quad$ vs. $51.1 \pm 9.0 \% \quad(35.2-76.7)$;
$P=0.068$ and 0.299 , respectively). The increases in GGT, BUN, STB, and DBIL in the 3D group were slightly lower than those in the 2D group, without significant statistical differences $(26.5 \pm 17.6 \mathrm{U} / \mathrm{L}$ (9.4-64.2) vs. $37.8 \pm 19.1 \mathrm{U} / \mathrm{L}(8.8-92.8), 4.4 \pm 2.6 \mathrm{mmol} / \mathrm{L}(1.3-13.8)$ vs. $6.6 \pm 5.3 \mathrm{mmol} / \mathrm{L}(2.4-18.1) ; 28.0 \pm 14.4 \mathrm{U} / \mathrm{L}(8.7-70.7)$ vs. $32.4 \pm 14.2 \mathrm{U} / \mathrm{L} \quad(3.8-74.1) ; 8.4 \pm 4.6 \mathrm{U} / \mathrm{L} \quad(1.2-17.7)$ vs. $10.6 \pm 10.0 \mathrm{U} / \mathrm{L}(3.4-49.4) ; P=0.060,0.061,0.252$, and 0.428 , respectively). One patient developed a case of acute kidney injury shortly after ablation in the $2 \mathrm{D}$ group and recovered after 12 hemodialysis episodes and 1 month of medical treatment.

\section{Discussion}

Concerning the treatment of symptomatic LHHs, a benign neoplasm, the primary goal is to relieve clinical symptoms and reduce the risk of rupture and bleeding. There are many therapeutic options, including surgical 
resection, transcatheter arterial embolization, thermal ablation, steroid treatment, radiation therapy, hepatic arterial ligation, and thermal ablation. Image-guided thermal ablation has been broadly applied clinically due to its advantages of minimal invasion, safety, convenience, efficacy, tolerability, and a shorter recovery time. Hepatic hemangiomas are benign tumors of the liver that consist of clusters of blood-filled cavities (sinusoids), lined by endothelial cells and fed by the hepatic artery [44].

The typical cause of hemangioma formation is abnormal vascular development during embryonic development due to a lack of smooth muscle tissue in abnormal blood vessels, leading to slow blood flow, blood stagnation, and slow heat dissipation [1]. MWA has the advantages of a broader thermal range and a more even spread, rapid heating speed, and reduced influence of carbonization and blood-flow perfusion; furthermore, multiple antennas can conduct ablation simultaneously without interference, exerting a synergistic effect, thus achieving a broader ablation range and shorter ablation time. Thus, MWA is the most suitable choice [11, 45].

The complex association between LHH and the surrounding vital structures could increase the difficulty and risk of treatment, prolong the operation time, increase ablation energy requirements, and potentially lead to damage to veins, bile ducts, or the intestinal tract and incomplete ablation [46-50]. It has been reported, based on a multivariate analysis, that the ablation time was an independent risk factor associated with hemoglobinuria $[10,45]$. In this comparative study, the data showed that the ablation time and energy of the 3D group were lower than those of the 2D group. The 3D group had a higher complete ablation rate than the $2 \mathrm{D}$ group. The incidence of hemoglobinuria after ablation in the 3D group was lower than that of the 2D group. The effects on hepatic and renal function in the 3D group were milder than those in the 2D group. These results indicate that the 3D preoperative planning system provided valuable anatomical information regarding the LHHs and surrounding organs, displayed stereoscopically.

The calculation of the tumor volume, programming of the antenna implantation, and precise prediction of the thermal field were also well planned, enabling a safe, precise, and successful ablation. The influence on renal function was reduced and the incidence of hemoglobinuria was lower with the $3 \mathrm{D}$ visualization operative planning system. The results indicated that the LHHs were ablated, rather than normal liver tissue. Conformal ablation was achieved with combination therapy. There was no thermal damage to the veins, bile ducts, and intestinal tract attributed to the auxiliary techniques, such as hydrodissection and thermal monitoring techniques $[11,51]$.

In ablation therapy, the tumor volume reduction rate is primarily dependent on the percentage of tumor ablation. The edge of LHHs is moved farther from high risk organs due to volume reduction after the ablation process, which leads to the relief of clinical symptoms. While incomplete ablation can occur and hepatic and renal function can be markedly affected, "eccentric ablation therapy" can be achieved in some cases. Although no significant differences were identified, the volume reduction rate of the $3 \mathrm{D}$ visualization operative planning group was slightly higher. These data further suggest the importance of the 3D visualization operative planning system in LHH ablation.

Serious complications should not occur in the treatment of benign lesions, including LHHs. One case of acute kidney injury shortly after ablation, with recovery after 12 hemodialysis treatments and 1 month of medical treatment, occurred in the 2D group. For this patient, the LHH maximum diameter was $8.6 \mathrm{~cm}$ and the volume was $295.29 \mathrm{ml}$, which was not the largest LHH included in this study. The ablation time was $1980 \mathrm{~s}$ and the ablation energy was $326,400 \mathrm{~J}$; both of these variables are risk factors for complications. The ALT, AST, and Cre levels after ablation were $489 \mathrm{U} / \mathrm{L}, 1063.1 \mathrm{U} / \mathrm{L}$, and $227 \mu \mathrm{mol} / \mathrm{L}$, respectively, which were markedly increased from the pre-treatment values $(17.3 \mathrm{U} / \mathrm{L}, 20.8 \mathrm{U} / \mathrm{L}$, and $75.3 \mu \mathrm{mol} / \mathrm{L}$, respectively), which indicates that more liver tissue was ablated, as verified by imaging. However, more treatments administered to patients may increase mental stress. Scientific, objective, quantifiable, and individualized operative planning are key issues for safe and effective ablation.

Although this study was a comparative study, there are several limitations. First, this study was a retrospective investigation; thus, a prospective, randomized, controlled trial would provide more scientifically valid data. Second, the study was performed in a single institution with a relatively small sample. The results should be confirmed by another cohort or a prospective, multicenter study with a larger sample size. Third, with the development and incorporation of applied mathematics, physics, and medicine, a more quantifiable, predictable, and controllable 3D visualization operative planning system may be developed that will provide more benefits for patients and operators.

\section{Conclusion}

The 3D visualization operation planing system provided more spatial imaging information and data on the relationship of the tumor with the surrounding structures; it also quantified the ablation techniques and the thermal field, providing scientific, objective, reasonable, quantifiable, and individualized operative planning for US-PMWA of LHHs. These factors are key issues for safe and effective ablation. Compared with the 2D group, the 3D group showed a higher complete ablation rate and a comparable reduction volume rate, with less effects on hepatic and renal function 
and a lower incidence of hemoglobinuria. Therefore, the $3 \mathrm{D}$ visualization operative treatment planning system has a relatively high clinical application value for use with US-PMWA for LHHs.

\section{Abbreviations}

2D: Two-dimensional; 3D: Three dimensional; ALP: Alkaline phosphatase; ALT: Alanine aminotransferase; AST: Aspartate aminotransferase; BUN: Blood urea nitrogen; CDFI: Color Doppler flow imaging; CEUS: Contrast-enhanced ultrasound; Cre: Creatinine; CT: Computed tomography; DBIL: Direct bilirubin; GGT: Gamma-glutamyl transpeptidase; LHHs: Large hepatic hemangiomas; MRI: Magnetic resonance imaging; PTC: Percutaneous transhepatic cholangiography; SD: Standard deviation; TB: Total bilirubin; US: Ultrasound; US-PMWA: Ultrasound-guided percutaneous microwave ablation

\section{Acknowledgements}

Not applicable.

\section{Funding}

This work was supported by the National Key R\&D Program of China (No. 2017YFC0112000), three grants from the National Scientific Foundation Committee of China (No. 81430039, 81627803 and 81801723), and the Clinical Research Support Foundation of the Chinese PLA General Hospital (No. 2017FCCXYY-3005). The funders had no role in the design and conduct of the study; collection, analysis, and interpretation of the data; preparation, review, or approval of the manuscript; and decision to submit the manuscript for publication.

\section{Availability of data and materials}

The datasets generated and/or analyzed during the current study will be available on reasonable request by contacting Dr. Xin Li (lixin301@hotmail.com).

\section{Authors' contributions}

$\mathrm{XL}$ participated in the data analysis and drafted the manuscript. PL conceived the study and carried out the editorial support for this manuscript. PL, JY, ZGC.,ZYH, FYL, XLY, CA and LND participated in the ablation procedure. XL, FYL, $C A$ and $L N D$ participated in the 3D visualization operative planning, and $X L$ and CA participated in image collection. All authors have read and approved the final manuscript.

\section{Ethics approval and consent to participate}

This retrospective study protocol was approved by the Ethics Committee of the Chinese PLA General Hospital (Beijing, China) and was conducted in accordance with the principles of the Declaration of Helsinki. Consent to participate was obtained from every participant.

\section{Consent for publication}

Not applicable.

\section{Competing interests}

The authors declare that they have no competing interests.

\section{Publisher's Note}

Springer Nature remains neutral with regard to jurisdictional claims in published maps and institutional affiliations.

\section{Received: 2 December 2018 Accepted: 7 May 2019}

Published online: 07 June 2019

\section{References}

1. Mergo PJ, Ros PR. Benign lesions of the liver. Radiol Clin N Am. 1998;36:319-31.

2. Belli L, De Carlis L, Beati C, Rondinara G, Sansalone V, Brambilla G. Surgical treatment of symptomatic giant hemangiomas of the liver. Surg Gynecol Obstet. 1992;174:474-8.

3. Gao J, Fan RF, Yang JY, Cui Y, Ji JS, Ma KS, et al. Radiofrequency ablation for hepatic hemangiomas: a consensus from a Chinese panel of experts. World J Gastroenterol. 2017;23:7077-86.
4. Tang L, Zhou WP. Education and imaging. Hepatobiliary and pancreatic: large cavernous hemangioma with obstructive jaundice. J Gastroentero Hepatol. 2009;24:930.

5. Srinivasa S, Lee WG, Aldameh A, Koea JB. HPB (Oxford). 2015;17:872-80.

6. Watzke HH, Linkesch W, Hay U. Giant hemangioma of the liver (Kasabach-Merritt syndrome): successful suppression of intravascular coagulation permitting surgical removal. J Clin Gastroenterol. 1989;11: 347-50.

7. Schnelldorfer T, Ware AL, Smoot R, Schleck CD, Harmsen WS, Nagorney DM. Management of giant hemangioma of the liver: resection versus observation. J Am Coll Surg. 2010;211:724-30.

8. Tang XY, Wang Z, Wang T, Cui D, Zhai B. Efficacy, safety and feasibility of ultrasound-guided percutaneous microwave ablation for large hepatic hemangioma. J Dig Dis. 2015;16:525-30.

9. Mocchegiani F, Vincenzi P, Coletta M, Agostini A, Marzioni M, Baroni GS, et al. Prevalence and clinical outcome of hepatic haemangioma with specific reference to the risk of rupture: a large retrospective cross-sectional study. Dig Liver Dis. 2016;48:309-14.

10. Liu F, Yu X, Cheng Z, Han Z, Dou J, Yu J, et al. Risk factors for hemoglobinuria after ultrasonography-guided percutaneous microwave ablation for large hepatic cavernous hemangiomas. Oncotarget. 2018:9:25708-13.

11. Liu F, Yu X, Liang P, Cheng Z, Han Z, Yu J. Ultrasonography-guided percutaneous microwave ablation for large hepatic cavernous haemangiomas. Int J Hyperthermia. 2018;34:1061-6.

12. van Tilborg AA, Nielsen $K$, Scheffer $H J$, van den Tol $P$, van Waesberghe $J H$, Sietses $C$, et al. Bipolar radiofrequency ablation for symptomatic giant ( $>10$ $\mathrm{cm})$ hepatic cavernous haemangiomas: initial clinical experience. Clin Radiol. 2013:68:e9-e14.

13. Toro A, Mahfouz AE, Ardiri A, Malaguarnera M, Malaguarnera G, Loria F, et al. What is changing in indications and treatment of hepatic hemangiomas. A review. Ann Hepatol. 2014;13:327-39.

14. Di Carlo I, Koshy R, Al Mudares S, Ardiri A, Bertino G, Toro A. Giant cavernous liver hemangiomas: is it the time to change the size categories? Hepatobiliary \& pancreatic diseases international : HBPD INT, vol. 15; 2016. p. 21-9.

15. Hoekstra LT, Bieze M, Erdogan D, Roelofs JJ, Beuers UH, van Gulik TM. Management of giant liver hemangiomas: an update. Expert Rev Gastroenterol Hepatol. 2013;7:263-8.

16. Miura JT, Amini A, Schmocker R, Nichols S, Sukato D, Winslow ER, et al. Surgical management of hepatic hemangiomas: a multi-institutional experience. HPB (Oxford). 2014;16:924-8.

17. Li M, Zhang C, Zhang T, Wang L, Ding Y, Niu Z, et al. Outcome using selective hemihepatic vascular occlusion and Pringle maneuver for hepatic resection of liver cavernous hemangioma. World J Surg Oncol. 2015;13:267.

18. Zhang W, Huang ZY, Ke CS, Wu C, Zhang ZW, Zhang BX, et al. Surgical treatment of Giant liver hemangioma larger than $10 \mathrm{~cm}$ : a single Center's experience with 86 patients. Medicine. 2015;94:e1420.

19. Giavroglou C, Economou H, loannidis I. Arterial embolization of giant hepatic hemangiomas. Cardiovasc Intervent Radiol. 2003;26:92-6.

20. Huang $X Q$, Huang $Z Q$, Duan WD, Zhou NX, Feng YQ. Severe biliary complications after hepatic artery embolization. World J Gastroenterol. 2002:8:119-23.

21. Firouznia K, Ghanaati H, Alavian SM, Nassiri Toosi M, Ebrahimi Daryani N, Jalali $\mathrm{AH}$, et al. Management of liver hemangioma using trans-catheter arterial embolization. Hepat Mon. 2014;14:e25788.

22. Bailey J, Di Carlo S, Blackwell J, Gomez D. Same day arterial embolisation followed by hepatic resection for treatment of giant haemangioma. BMJ Case Rep. 2016. https://doi.org/10.1136/bcr-2015-213259.

23. Park WC, Rhillips $R$. The role of radiation therapy in the management of hemangiomas of the liver. JAMA. 1970;212:1496-8.

24. Gaspar L, Mascarenhas F, da Costa MS, Dias JS, Afonso JG, Silvestre ME. Radiation therapy in the unresectable cavernous hemangioma of the liver. Radiother Oncol. 1993;29:45-50.

25. Zagoria RJ, Roth TJ, Levine EA, Kavanagh PV. Radiofrequency ablation of a symptomatic hepatic cavernous hemangioma. AJR Am J Roentgenol. 2004;182:210-2

26. Park SY, Tak WY, Jung MK, Jeon SW, Cho CM, Kweon YO, et al. Symptomatic-enlarging hepatic hemangiomas are effectively treated by percutaneous ultrasonography-guided radiofrequency ablation. J Hepatol. 2011;54:559-65 
27. Gao J, Ji JS, Ding XM, Ke S, Xin ZH, Ning CM, et al. Laparoscopic radiofrequency ablation for large subcapsular hepatic hemangiomas: technical and clinical outcomes. PLoS One. 2016;11:e0149755.

28. Mahajan D, Miller C, Hirose K, McCullough A, Yerian L. Incidental reduction in the size of liver hemangioma following use of VEGF inhibitor bevacizumab. J Hepatol. 2008:49:867-70.

29. Yamashita S, Okita K, Harada K, Hirano A, Kimura T, Kato A, et al. Giant cavernous hepatic hemangioma shrunk by use of sorafenib. Clin J Gastroenterol. 2013:6:55-62.

30. Aslan A, Meyer Zu Vilsendorf A, Kleine M, Bredt M, Bektas H. Adult Kasabach-Merritt syndrome due to hepatic Giant hemangioma. Case Rep Gastroenterol. 2009;3:306-12.

31. Vagefi PA, Klein I, Gelb B, Hameed B, Moff SL, Simko JP, et al. Emergent orthotopic liver transplantation for hemorrhage from a giant cavernous hepatic hemangioma: case report and review. J Gastrointest Surg. 2011;15:209-14

32. Wright AS, Sampson LA, Warner TF, Mahvi DM, Lee FT Jr. Radiofrequency versus microwave ablation in a hepatic porcine model. Radiology. 2005;236:132-9.

33. Yu J, Yu XL, Han ZY, Cheng ZG, Liu FY, Zhai HY, et al. Percutaneous cooled-probe microwave versus radiofrequency ablation in early-stage hepatocellular carcinoma: a phase III randomised controlled trial. Gut. 2017:66:1172-3.

34. Ziemlewicz TJ, Wells SA, Lubner MA, Musat Al, Hinshaw JL, Cohn AR, et al. Microwave ablation of giant hepatic cavernous hemangiomas. Cardiovasc Intervent Radiol. 2014;37:1299-305.

35. Aydin C, Akbulut S, Kutluturk K, Kahraman A, Kayaalp C, Yilmaz S. Giant hepatic hemangioma presenting as gastric outlet obstruction. Int Surg. 2013;98:19-23

36. Koszka AJ, Ferreira FG, de Aquino CG, Ribeiro MA, Gallo AS, Aranzana EM, et al. Resection of a rapid-growing 40-cm giant liver hemangioma. World J Hepatol. 2010;2:292-4

37. Zhou JX, Huang JW, Wu H, Zeng Y. Successful liver resection in a giant hemangioma with intestinal obstruction after embolization. World J Gastroenterol. 2013;19:2974-8.

38. van Tilborg A, Dresselaars HF, Scheffer HJ, Nielsen K, Sietses C, van den Tol PM, et al. RF ablation of Giant hemangiomas inducing acute renal failure: a report of two cases. Cardiovasc Intervent Radiol. 2016:39:1644-8.

39. Liu F, Liang $P, Y u X, L u T$, Cheng Z, Lei $C$, et al. A three-dimensional visualisation preoperative treatment planning system in microwave ablation for liver cancer: a preliminary clinical application. Int J Hyperthermia. 2013;29:671-7.

40. Schumann C, Bieberstein J, Braunewell S, Niethammer M, Peitgen HO Visualization support for the planning of hepatic needle placement. Int Comput Assist Radiol Surg. 2012;7:191-7.

41. Wu W, Xue Y, Wang D, Li X, Xue J, Duan S, et al. Application of 3D imaging in the real-time US-CT fusion navigation for minimal invasive tumor therapy. Int J Comput Assist Radiol Surg. 2015;10:1651-8.

42. Li X, Yu J, Liang P, Yu X, Cheng Z, Han Z, et al. Combination therapy of three-dimensional (3D) visualisation operative treatment planning system and US-guided percutaneous microwave ablation in larger renal cell carcinomas (D >/= 4 cm): preliminary results. Int J Hyperthermia. 2017;33(3): 271-7.

43. Sacks D, McClenny TE, Cardella JF, Lewis CA. Society of Interventional Radiology clinical practice guidelines. J Vasc Interv Radiol. 2003;14:S199-202.

44. Bajenaru N, Balaban V, Savulescu F, Campeanu I, Patrascu T. Hepatic hemangioma -review. J Med Life. 2015;8(Spec Issue):4-11.

45. Wang Z, Tang X, Qi X, Shi Y, Chi J, Li P, et al. Feasibility, safety, and efficacy of ultrasound-guided percutaneous microwave ablation for giant hepatic hemangioma. Int J Hyperthermia. 2018;35(1):246-52.

46. Groeschl RT, Riggle KM, Quebbeman EJ, Christians KK, Turaga KK, Tsai S, et al. Hepatectomy for hemangioma; safe, but is it successful? Hepatogastroenterology. 2014;61:2009-13.

47. Gao J, Ke S, Ding XM, Zhou YM, Qian XJ, Sun WB. Radiofrequency ablation for large hepatic hemangiomas: initial experience and lessons. Surgery. 2013;153:78-85.

48. Choi J, Lee YJ, Hwang DW, Chon SH, Nagpal A, Park KM. Surgical treatment of giant hepatic hemangiomas: technical point of view. Am Surg. 2011;77:48-54.

49. Ho HY, Wu TH, Yu MC, Lee WC, Chao TC, Chen MF. Surgical management of giant hepatic hemangiomas: complications and review of the literature. Chang Gung Med J. 2012;35:70-8.
50. Zenzen W, Perez-Atayde AR, Elisofon SA, Kim HB, Alomari Al. Hepatic failure in a rapidly involuting congenital hemangioma of the liver: failure of embolotherapy. Pediatr Radiol. 2009;39:1118-23.

51. Zhang D, Liang $P, Y u X$, Cheng Z, Han Z, Yu J, et al. The value of artificial pleural effusion for percutaneous microwave ablation of liver tumour in the hepatic dome: a retrospective case-control study. Int J hyperthermia. 2013;29:663-70.
Ready to submit your research? Choose BMC and benefit from:

- fast, convenient online submission

- thorough peer review by experienced researchers in your field

- rapid publication on acceptance

- support for research data, including large and complex data types

- gold Open Access which fosters wider collaboration and increased citations

- maximum visibility for your research: over $100 \mathrm{M}$ website views per year

At BMC, research is always in progress.

Learn more biomedcentral.com/submissions 